For this the published data are insufficient, and we must await studies in which normal as well as malformed births to takers and non-takers of sodium valproate are fully represented. Meanwhile, women who have taken the drug in early pregnancy should perhaps be offered an amniocentesis to check the concentration of $\alpha$-fetoprotein in the amniotic fluid.

The third and most contentious question concerns the hypothesis that vitamin supplements during pregnancy prevent defects of the neural tube. Other publications ${ }^{22} 23$ have reviewed the observations which support this hypothesis: evidence from studies in animals, experience with the use of drugs which are antagonists of folic acid, seasonal and social class variations in prevalence and nutrition, correlations between the outcome of pregnancy and concentrations of vitamins in the blood in early pregnancy, and, finally, the apparent success of two clinical trials of vitamin supplements given in the periconceptional period to women who had previously produced affected children. Even these trials, however, do not prove conclusively that vitamin supplements prevent defects of the neural tube. In the first trial, a double blind comparison of folic acid and a placebo, the difference in the outcome of pregnancy was not statistically significant. ${ }^{24}$ The second study, using a combination of folate and other vitamins, was not a randomised controlled trial and compared women who accepted vitamins before conception with those who either declined them or who were already pregnant. ${ }^{25}{ }^{26} \mathrm{~A}$ further limitation of this trial was that it could not indicate which specific vitamin, if any, might prevent congenital defects.

Because of these limitations the Medical Research Council is launching a further trial in mothers of affected children who wish to conceive again. Participants will be randomly distributed among four groups to receive pills in which minerals will either be the only active ingredients or be combined with folate, with other vitamins, or with both. ${ }^{27}$

This trial is intended to show whether vitamin supplements can reduce the recurrence rates of defects of the neural tube to the extent suggested by the second trial (about sixfold). It will succeed, however, only if there is no great decline in "natural" recurrence rates and if the intended number of participants-at least 2000 - can be recruited and then restrained from taking other vitamin preparations. It will be surprising if all these provisions are satisfied. With the current decline in prevalence we may expect recurrence rates to fall, since the two tend to vary concordantly. ${ }^{4829}$ Even more important, any normal mother of an affected child who is told (as potential participants must be) that vitamin supplementation may possibly prevent recurrence and that entering the trial may mean forgoing such treatment will surely decline to participate. Her family doctor will probably back this decision, especially since the advice recently proffered in the $B M \mathcal{F}$ was that "folate should be given to any woman with a .. . history of a child with spina bifida or anencephaly" who wishes to conceive..$^{30} \mathrm{~A}$ more practicable and ethical way to reassess whether or not vitamin supplements reduce recurrence rates might be to look at how these rates have changed in the recent past. In periods and places in which vitamin supplements have been widely used one would expect to find a lower overall recurrence rate than elsewhere if supplementation were really effective, but not if the differences observed between supplemented and unsupplemented pregnancies were due only to self selection.

IAN LECK

Professor of Community Medicine, University of Manchester, Manchester M13 9PT
1 Record RG, McKeown $T$. Congenital malformations of the central nervous system: I. A survey of 930 cases. British fournal of Social Medicine $1949 ; 3: 183-219$.

${ }^{2}$ McKeown T, Record RG. Seasonal incidence of congenital malformations of the central nervous system. Lancet $1951 ; \mathrm{i}: 192-6$.

${ }^{3}$ Elwood JM, Elwood JH. Epidemiology of anencephalus and spina bifida. Oxford: Oxford University Press, 1980.

4 Leck I. Epidemiological clues to the causation of neural tube defects. In: Dobbing J, ed. Prevention of spina bifida and other neural tube defects. London: Academic Press, 1983:155-82.

5 WHO Scientific Group on Genetic Factors in Congenital Malformations. Genetic factors in congenital malformations. WHO Tech Rep Ser 1970 ; No 438.

${ }^{6}$ Rogers SC, Weatherall JAC. Anencephalus, spina bifida and congenital hydrocephalus: England and Wales, 1964-1972. London: HMSO, 1976. (Studies on medical and population subjects, No 32.)

${ }^{7}$ Office of Population Censuses and Surveys. Congenital malformations. London: HMSO, 1982. (OPCS Monitor, MB3 82/3, 82/4.)

${ }^{8}$ Nevin NC. Neural tube defects. Lancet 1981 ;ii:1290-1.

${ }^{9}$ Stein SC, Feldman JG, Friedlander M, Klein RJ. Is myelomeningocele a disappearing disease? Pediatrics 1982;69:511-4.

10 Windham GC, Edmonds LD. Current trends in the incidence of neural tube defects. Pediatrics 1982;70:333-7.

${ }^{11}$ Field B, Kerr C, Mathers CD. Incidence of neural-tube defects. Dev Med Child Neurol 1982;24:861-2.

${ }^{12}$ Danks DM, Halliday JL. Incidence of neural tube defects in Victoria, Australia. Lancet 1983;i:65.

${ }^{13}$ Kirke P. Epidemiological clues to the causation of neural tube defects: discussion. In: Dobbing J, ed. Prevention of spina bifida and other neural tube defects. London: Academic Press, 1983:191-2.

14 Owens JR, Harris F, McAllister E, West L. 19-Year incidence of neural tube defects in area under constant surveillance. Lancet 1981 ;ii:1032-5.

15 Leck I. Epidemiological clues to the causation of neural tube defects: discussion. In: Dobbing J, ed. Prevention of spina bifida and other neural tube defects. London: Academic Press, 1983:185-7.

16 Janerich DT. Epidemic waves in the prevalence of anencephaly and spina bifida in New York State. Teratology 1973;8:253-6.

${ }^{17}$ Romijn JA, Treffers PE. Anencephaly in the Netherlands: a remarkable decline. Lancet $1983 ; \mathrm{i}: 64-5$.

${ }^{18}$ Brown NA, Kao J, Fabro S. Teratogenic potential of valproic acid. Lancet 1980;i:660-1.

19 Bjerkedal T, Czeizel A, Goujard J, et al. Valproic acid and spina bifida. Lancet 1982;ii:1096.

${ }^{20}$ Jeavons PM. Sodium valproate and neural tube defects. Lancet 1982 ;ii 1282-3.

${ }^{21}$ Smithells RW. Environmental teratogens of man. Br Med Bull 1976;32: 27-33.

${ }^{22}$ Anonymous. Spina bifida: controversy over tests continues. Nature 1982;300:396-7.

${ }^{23}$ Dobbing J, ed. Prevention of spina bifida and other neural tube defects. London: Academic Press, 1983.

${ }^{24}$ Laurence KM, James N, Miller MH, Tennant GB, Campbell $H$. Double-blind randomised controlled trial of folate treatment before conception to prevent recurrence of neural-tube defects. $\mathrm{Br} \mathrm{Med} \mathcal{J}$ $1981 ; 282: 1509-11$.

${ }^{25}$ Smithells RW, Sheppard S, Schorah CJ, et al. Apparent prevention of neural tube defects by periconceptional vitamin supplementation. Arch Dis Child $1981 ; 56: 911-8$.

${ }^{26}$ Smithells RW, Nevin NC, Seller MJ, et al. Further experience of vitamin supplementation for prevention of neural tube defect. Lance $1983 ; \mathrm{i}: 1027-31$

${ }^{27}$ Wynn J. Spina bifida: trials ahead. Nature $1982 ; 299: 198$.

${ }^{28}$ Yen S, MacMahon B. Genetics of anencephaly and spina bifida ? Lancet 1968;ii :623-6.

29 Nevin NC. Recurrence risk of neural tube defects. Lancet 1980;1:1301-2.

${ }^{30}$ Bull MJV. Pregnancy. Br Med f 1982;284:1611-2.

\section{Pregnancy in patients with prosthetic heart valves}

Patients who have had palliative or corrective cardiac surgery for congenital or acquired heart disease are being seen increasingly often as candidates for antenatal cardiac care. Cardiac surgery is usually not curative and each such patient requires individual assessment. The chances of success depend on their haemodynamic state, the effects of pregnancy on this and on fetal development, the likelihood of thromboembolic or infective complications, the possible effects on the child of 
drugs given to the mother, and (in certain cases) the risks of the child inheriting the parental disease.

Women with prosthetic heart valves pose particular problems. Their haemodynamic reserve is usually more than adequate for safe pregnancy, ${ }^{1}$ and the risk of infective endocarditis from bacteraemia during delivery appears very small. ${ }^{2}$ The problem is that unless anticoagulants are given ${ }^{3}$ the risk of thromboembolism is increased-probably because of the hypercoagulable state in pregnancy, ${ }^{4}$ when concentrations of clotting factors and platelet activity are increased and fibrinolytic activity is diminished..$^{56}$

Unfortunately the use of coumarin anticoagulants in pregnancy causes concern because of their teratogenic and haemorrhagic effects, and some authorities have suggested that a need for anticoagulants is a contraindication to pregnancy. ${ }^{7}$ The main teratogenic effect of warfarin is a defect in the ossification of bone, "chondrodysplasia punctata"; affected infants may have optic atrophy, deafness, and deformities of the limbs. The syndrome occurs only when warfarin is taken between the sixth and ninth weeks of gestation, and most damaged fetuses are aborted spontaneously. ${ }^{7}$ Defects in the central nervous system may occur when warfarin is taken at any stage of pregnancy $^{78}$ and almost certainly result from microhaemorrhage into the brain. Fetal haemorrhage is an unavoidable risk since the dosage of warfarin that is correct for the mother leads to overanticoagulation of the fetus, whose liver enzyme systems are immature. (Maternal prothrombins are large molecules and do not cross the placenta.)

Indanedione anticoagulants have no teratogenic proclivity but they reach the fetus in the same way as coumarins such as warfarin, and they may also cause serious hepatic and renal toxicity, so that drugs from the coumarin group are usually preferred. The risk of fetal damage from coumarins has been difficult to determine because the individual experience of most clinicians is small and most publications are anecdotal. Hall et al estimated that only about two thirds of pregnancies will be successful. ${ }^{7}$ They showed that although fetal wastage was high the number of liveborn deformed babies was small: two embryopathies out of 201 pregnancies in which warfarin was given in the first trimester, and none out of 152 babies exposed to coumarins during the second and third trimesters.

Heparin has been advocated as a possibly superior alternative, because heparin given to the mother does not reach the fetus at all. On the other hand, heparin has not been shown to be effective in preventing arterial thromboembolism in pregnancy, and thrombosis affecting prosthetic valves has also been reported. ${ }^{9}$ Moreover, to avoid warfarin embryopathy treatment with heparin would need to be started before the sixth to ninth weeks, so threatening all the complications of its long term use. Unfortunately the use of heparin is associated with an equally high incidence of fetal loss from abortion, premature birth, and stillbirth caused by placental separation. Hall et al found that only 86 out of 135 reported pregnancies had produced healthy full term babies. There were three maternal deaths and 14 women developed complications due to bleeding. Other complications of long term subcutaneous heparin included anaphylaxis, osteoporosis, painful nodules, and alopecia; in addition technical difficulties in administration may cause problems.

A personal experience of 41 pregnancies in 24 women was recently described from Hong Kong, ${ }^{10}$ a larger experience than any previous series. The higher continuing incidence of rheumatic fever in Hong Kong was reflected in the fact that all the patients had mitral prostheses, all patients having mechanical valves except for one woman with a Hancock valve. Nine women had 11 pregnancies without anticoagulants, but one mother died from cerebral embolism, and one needed surgery at 32 weeks because of pulmonary oedema caused by a thrombosed valve. This last baby did well, as did nine of the others; there was one abortion.

Warfarin was given during 29 pregnancies. The intention was to substitute subcutaneous heparin for warfarin in the first trimester, but in 10 pregnancies this could not be done and eight of these resulted in abortion. Only one patient was treated with heparin throughout pregnancy. All 30 mothers treated with anticoagulants did well, but one had a non-fatal cerebral embolism in the puerperium while receiving subcutaneous heparin. There were 10 abortions and 20 healthy babies, all of whom did well. No warfarin embryopathy was seen. One surviving baby had hydrocephalus (probably caused by intraventricular haemorrhage) and one a cleft palate.

Three patients were treated with only dipyridamole and aspirin and did well, but when given on their own drugs that influence platelet behaviour are not effective in preventing thromboembolism from artificial valves and are likely to be even less effective in pregnancy. ${ }^{11} 12$

The possibility that the patient might wish to become pregnant has been used as an indication for a tissue valve, ${ }^{12}$ but the risk of thromboembolism is not negligible, and anticoagulants are necessary when the left atrium is large or fibrillating. ${ }^{13}$ Unfortunately, the long term durability of these valves is now proving disappointing, particularly in the young, ${ }^{14}$ and the elective placement of a temporary valve in a young woman is unacceptable just to increase the chance of successful pregnancy.

The experience gained suggests that the risk of pregnancy is low for a woman with a prosthetic valve provided she continues treatment with warfarin. ${ }^{171015}$ Control should be painstaking to avoid overdosage. Though the risk of spontaneous abortion is high, the chances of having a liveborn abnormal baby are probably under $10 \%$. The patient should be admitted to hospital at least two weeks before the expected date of delivery (and earlier in primiparas) in order to exchange warfarin for intravenous heparin before the onset of labour. The action of the heparin is then reversed before delivery, but heparin treatment is restarted immediately afterwards, and continued until the warfarin effect is restored. Oxytocic drugs should not be omitted. If labour begins unexpectedly in a patient who is still receiving warfarin she should be given fresh frozen plasma and the baby given vitamin $\mathrm{K}_{1}$. Though antibiotic cover is probably unnecessary for normal delivery, many cardiologists will still choose to give it to women with prosthetic valves based on a "rather safe than sorry" philosophy.

For the conceptus the best chance would be to withhold both warfarin and heparin. The risks to the embryo, fetus, and baby of giving anticoagulants are greater than the risks to the mother of not giving them. But this is not an option: to submit the mother to increased risk for any reason is unthinkable. The risk ratios need to be borne in mind to put case reports into perspective. Reports of isolated successful pregnancies in which the mothers were treated with heparin, warfarin, or drugs which influence platelets or with nothing at all do not indicate that such regimens are safe. Either success or failure may stimulate reporting, so it is rather remarkable that the large series collected from a review of the published reports ${ }^{7}$ indicates a similarity of combined experience to that reported in smaller series gained personally. ${ }^{1011}$

Celia Oakley

Consultant Cardiologist,

Royal Postgraduate Medical School,

London W12 0HS 
${ }^{1}$ Oakley $\mathrm{C}$, Doherty $\mathrm{P}$. Pregnancy in patients after valve replacement. $\mathrm{Br}$ Heart $\mathcal{F} 1976 ; 38: 1140-8$.

2 Sugrue D, Blake S, Troy P, MacDonald D. Antibiotic prophylaxis against infective endocarditis after normal delivery-is it necessary? Br Heart 7 1980;44:499-502.

${ }^{3}$ McLeod AA, Jennings KP, Townsend ER. Near fatal puerperal thrombosis on Björk-Shiley mitral valve prosthesis. Br Heart $\mathcal{F} 1978$;40:934-7.

4 Todd ME, Thompson JH Jr, Bowie ETJ, Owen LA. Changes in blood coagulation during pregnancy. Mayo Clin Proc 1965;40:370-83.

5 Shaper AG, Macintosh DM, Evans CM, Kyobe J. Fibrinolysis and plasminogen levels in pregnancy and the puerperium. Lancet 1965;ii:706-8.

6 Brakman P. The fibrinolytic system in human blood during pregnancy. Am $\mathcal{F}$ Obstet Gynecol 1966;94:14-20.

7 Hall JG, Pauli RM, Wilson KM. Maternal and fetal sequelae and anticoagulation during pregnancy. Am $\mathcal{F}$ Med 1980;68:122-40.

$\checkmark$ Villasanta U. Thromboembolic disease in pregnancy. Am $\mathcal{F}$ Obstet Gynecol $1965 ; 93: 142-60$.

${ }^{9}$ Bennett GG, Oakley CM. Pregnancy in a patient with a mitral-valve prosthesis. Lancet 1968; :616-9.

${ }^{10}$ Chen WWC, Chan CS, Lee PK, Wang RYC, Wong VCW. Pregnancy in patients with prosthetic heart valves: an experience with 45 pregnancies. $Q \mathcal{F}$ Med 1982;203:358-65.

${ }^{11}$ Ibarra-Perez C, Arevalo-Toledo N, Alvarez-De La Cadena, O, NoriegaGuerra $\mathrm{L}$. The course of pregnancy in patients with artificial heart valves. Am $\mathcal{F}$ Med 1976;61:504-12.

12 Anonymous. Anticoagulants and heart valve replacement in pregnancy. $\mathrm{Br}$ Med F 1977;i:1047-8.

13 Edmiston WA, Harrison EC, Duick GF, Parnassus W, Lau FYK. Thromboembolism in mitral porcine valve recipients. $\mathrm{Am} ₹ \mathrm{Cardiol}$ $1978 ; 41: 508-11$.

14 Curcio CA, Commerford PJ, Rose AG, Stevens JE, Barnard MS. Calcification of glutaraldehyde-preserved porcine xenografts in young patients. 7 Thorac Cardiovasc Surg $1981 ; 81: 621-5$.

15 Lutz DJ, Noller KL, Spittell JA, Danielson GK, Fish CR. Pregnancy and its complications following cardiac valve prostheses. Am $\mathcal{f}$ Obstet Gynecol $1978 ; 131: 460-8$.

\section{Epidemiology: a losing cause?}

Mortality statistics have been used for over three centuries to direct health services towards needs and to examine the outcomes of medical intervention-but they are only one measure by which epidemiological data can help monitor the outcome of health service policies. The report of the Royal Commission on the National Health Service stated ${ }^{1}$ that "Without explicit measures of the need of groups of patients for health care, rational decisions on priorities and geographical distribution of resources are impossible. The lack of outcome measures means that judgments of the efficiency of health service delivery rest on insecure foundations." Yet the first report of the Steering Group on Health Services Information, chaired by Mrs Edith Körner," has suggested a "district minimum data set" giving the administrative characteristics of patients passing through hospital but saying nothing about outcome. Hospital clinicians and community physicians will be left without the central information they need for effective management.

At the time of reorganisation of the NHS in 1974 several reviews showed that the information available for planning, management, and monitoring was unsatisfactory both in coverage and quality. ${ }^{3-6}$ The Department of Health and Social Security first tackled community health statistics, ${ }^{7}$ and then began to look more widely at the routine information being collected in the NHS. ${ }^{8}$ Seminars sponsored by the DHSS at the NHS Training and Studies Centre, Harrogate, ${ }^{9} 10$ discussed ways of encouraging hospital clinicians to make use of administrative data. The DHSS kept information as a priority after the 1979 change in government, and the joint DHSS-NHS Information Steering Group was established in February 1980. Its terms of reference were to review and suggest changes in health services information systems. But it $\frac{\text { wo }}{\frac{1}{2}}$ chose to interpret this brief narrowly, concentrating on $\stackrel{\Phi}{\circ}$ information "for the monitoring and control of resource $c$ utilisation."

Indeed, the steering group referred to the paragraph from the royal commission quoted above but rejected its view, $\mathbb{\Phi}_{\mathbb{D}}$ claiming that information about the occurrence of disease or about the health needs of populations was beyond the scope $?$ of its work and that data describing health state or the clinical and social outcomes of the use of health services were "not $\stackrel{\text { क }}{\rightarrow}$ sufficiently developed to allow their introduction" routinely.

Such logic is hard to follow. If the Health Service is to be $\frac{\bar{\sigma}}{\bar{\omega}}$ managed effectively, whether by clinicians themselves, the $\vec{\Phi}$ health authorities, or their officers, epidemiological information should be available describing the extent of health ${ }^{\infty}$ problems and whether the outcome of the service has been $\vec{\circ}$ useful. Information about the process of health care does not $\overrightarrow{\vec{\omega}}$ meet this need, except in the limited instance, for example, $\stackrel{\circ}{\circ}$ of describing the number of operations performed each year 3 for a given population.

How did the steering group make this decision? Of its 17 members, five represented community medicine-one $\mathcal{E}^{-}$ academic, one civil servant, and three working in the NHSbut no one at district level nor any epidemiologist from the $\vec{\sigma}$ Office of Population Censuses and Surveys. While the steering ${ }^{\circ}$ group may believe that the current information on need and $\mathrm{O}$ outcome is inadequate, so indeed is the administrative $N_{\infty}$ information, and the committee has put considerable effort 3 into improving that. Why were epidemiological measures excluded from this effort-at a time when many members of $\overrightarrow{0}$ district health authorities and community health councils are $\mathbb{E}^{\infty}$ becoming better informed about health care needs and the policy options that may lead to improvements in health ?11 120 The regional and district management teams need to learn each other's perspectives, and without epidemiological information clinicians and community physicians will be less $\frac{\mathbb{Q}}{\square}$ able to inform their non-medical colleagues. Further, the $\overrightarrow{\vec{A}}$ emphasis on process rather than diagnostic information 3 justifies administrators' expectations that the line management $\bar{F}$ of information services should be within the administrator's? hierarchy, leaving medical officers without adequate support, particularly at district level.

The cost of implementing the Körner steering group's recommendations will be high: the expense and effort of getting "minimum data sets" in each district and region willo leave precious little for developing epidemiological information. Indeed, the North East Thames region has recently abandoned cancer registration while pressing ahead with the steering o group's improvements in process information.

In a timely statement just published the presidents of the three Royal Colleges of Physicians and their Faculties of Community Medicine and Occupational Medicine, and the $\mathrm{W}$ Royal College of Psychiatrists, have come together to emphasise? the importance of epidemiology in medical practice. ${ }^{13}$ They recommend that training posts and programmes should bee established jointly between clinical specialties and academic departments of community medicine, with suitable accreditation for joint career posts, and they encourage the universities and the NHS departments of community medicine to give adequate $\stackrel{\mathbb{Q}}{\stackrel{\mathbb{P}}{2}}$ funding for these developments.

These are practical proposals, and could indeed be extended. All medical students in Britain now have some experience in epidemiology, though the understanding may be extinguished during their years of hospital residency. Courses in epidemiology and management should be available as post- 